\title{
Sex-associated Differences in Pre-Antiretroviral Therapy Plasma HIV-1 RNA in Diverse Areas of the World Vary by CD4 Cell Count
}

\author{
Beatriz Grinsztejn ${ }^{1}$, Laura Smeaton ${ }^{2}$, Ronald Barnett ${ }^{3}$, Karin Klingman ${ }^{4}$, James Hakim ${ }^{5}$, \\ Timothy Flanigan ${ }^{6}, \mathbf{N ~ K u m a r a s a m y}^{7}$, Thomas Campbell ${ }^{8}$, and Judith Currier ${ }^{9}$ on behalf of \\ the PEARLS study team of the ACTG
}

${ }^{1}$ Evandro Chagas Clinical Research Institute, Oswaldo Cruz Foundation, Manguinhos, Brazil ${ }^{2}$ Statistical \& Data Analysis Center, Harvard School of Public Health, Boston, Massachusetts, USA ${ }^{3}$ Office of Biotechnology Activities, National Institutes of Health, Bethesda, Maryland, USA ${ }^{4}$ HIV Research Branch, Division of AIDS, NIAID, NIH. Bethesda, MD, USA ${ }^{5}$ University of Zimbabwe College of Health Sciences, Harare, Zimbabwe ${ }^{6}$ Brown Medical School, Providence, Rhode Island ${ }^{7}$ YRG Centre for AIDS Research \& Education, Chennai, India ${ }^{8}$ University of Colorado Health Sciences Center, Denver, Colorado, USA ${ }^{9}$ University of California, CA, USA, Los Angeles, Los Angeles, California, USA4

\section{Abstract}

Background-Sex differences in the natural history of HIV infection may vary between resource-rich and resource-limited settings.

Objective-Baseline characteristics from a randomized clinical trial of treatment naïve subjects conducted at sites in Africa, Asia, the Caribbean, and North and South America were analyzed to determine if there were significant differences by sex.

Results-Of the 1571 participants, 740 (47.1\%) were women. Women had higher mean screening CD4 cell counts (average 15 cells higher, $(\mathrm{p}<0.001)$, lower mean hemoglobin and creatinine clearance, a lower mean baseline HIV-1 viral $\operatorname{load}(4.85 \log 10$ vs. $5.05 \log 10$ copies $/ \mathrm{mL}$ $(\mathrm{P}<0.001))$ and were less likely to have a prior AIDS diagnosis than men. The sex difference in viral load difference was related to CD4 cell count, however it was independent of country and persisted within the strata with CD4 $<200$ cells $/ \mathrm{mm}^{3}$.

Conclusion-Women in resource limited settings have lower levels of plasma HIV-1 RNA and appear to present for enrollment into a clinical trials at an earlier stage of disease than men. The biologic basis for lower viral in women compared to men remains unexplained. It will be important to determine if the sex differences observed at baseline impact clinical outcomes once the PEARLS clinical trial is completed.

\section{Keywords}

viral load; sex; international; clinical trial; CD4 cell count

Corresponding author : Beatriz Grinsztejn. Evandro Chagas Clinical Research, Institute, Oswaldo Cruz Foundation, Manguinhos, Brazil, Avenida Brasil 4365, Manguinhos, Zip Code 21040-900, Tel/Fax 5521 2270-7064, gbeatriz@ipec.fiocruz.br. 


\section{Introduction}

Half of the people living with HIV infection worldwide are female ${ }^{1}$ Prior studies describing lower levels of plasma HIV-1 RNA in women compared to men, particularly early in the course of the disease, were comprised of populations from resource-rich settings. ${ }^{2-6}$

As the availability of antiretroviral therapy (ART) expands globally, it is critical to assess potential sex differences in HIV pathogenesis and treatment outcomes. Because of differences in HIV clades and in the prevalence of co-morbidities, it is possible that sex differences in the HIV viral load set point may vary between resource-rich and resourcelimited settings and between countries within resource-limited settings. Although the ideal way to study the natural history of HIV infection is through longitudinal studies of recently infected individuals, the study of antiretroviral naïve patients with low CD4 counts allows to describe gender differences at a more advanced stage of the disease.

We analyzed potential sex-related differences in plasma HIV-1 RNA levels prior to the initiation of ART in a randomized trial conducted in Africa, Asia, the Caribbean, and North and South America. The main objectives of the analysis were to compare baseline demographic and clinical characteristics, CD4 cell counts and plasma HIV-1 RNA levels between treatment-naïve men and women starting ART.

\section{Methods}

The AIDS Clinical Trials Group Prospective Evaluation of Antiretrovirals in ResourceLimited Settings (PEARLS) study is a phase IV, prospective, randomized, open-label evaluation of the efficacy of once-daily protease inhibitor and once-daily non-nucleoside reverse transcriptase inhibitor antiretroviral combinations for the initial treatment of HIV-1infected individuals from eight resource-limited settings in Africa, Asia, the Caribbean, and North and South America(NCT00084136). The participants were $>18$ years old, had documented HIV-1 infection, had received no more than 7 days of cumulative prior ART (prior use of single-dose nevirapine or zidovudine for any duration to prevent mother-tochild transmission of HIV was allowed), and had a CD4 cell count $<300$ cells $/ \mathrm{mm}^{3}$ within 90 days prior to entry into the study. All the patients had clinical assessments for hepatitis B surface antigen and other clinical conditions at baseline. Informed consent was obtained from all participants, and the human experimentation guidelines of the US Department of Health and Human Services and local site institutional review boards and ethics committees were followed.

Plasma HIV-1 RNA levels were measured using the Roche Amplicor HIV-1 Monitor assay, and CD4 cell counts were measured by flow cytometry. All site laboratories were certified by the NIAID/DAIDS Virology Quality Assurance Program and the UK National External Quality Assessment Service.

This analysis was a cross-sectional evaluation of antiretroviral-naïve men and women enrolled in the PEARLS study. All analyses were exploratory and did not correct (either pvalues or confidence interval levels) for multiple comparisons. Comparisons of baseline demographics and other characteristics between men and women used Pearson chi-squared tests for categorical variables and t-tests for continuous variables. Linear regression modeling was used to predict baseline plasma HIV-1 viral loads, using screening CD4+ cell counts with sex as a covariate. Logistic regression was used to estimate odds ratios and to build multivariate models that controlled for the presence versus the absence of a prior AIDS diagnosis. Cochran-Mantel-Haenszel methods for contingency tables were also used to test the relationships between CD4 count, sex, and AIDS diagnosis, using a stratified twoby-two table analysis. Because country was hypothesized to be an important potential 
confounder, analyses (except where indicated) were either stratified or further controlled by country. All analyses were performed using SAS version 9.1 for the UNIX platform.

\section{Results}

Participants were enrolled between May 2005 and August 2007. Of the 1,571 participants, $740(47.1 \%)$ were women. Selected pre-treatment demographic, clinical, and laboratory values are summarized in Table 1. Enrolled women were more likely to be Black African (47.6\% of the women compared to $21.4 \%$ of the men, $\mathrm{p}<0.0001$ ) and less likely to be Hispanic (12.2\% of the women compared to $28.0 \%$ of the men, $\mathrm{p}<0.001)$. The mean age of the study population was 35.2 years (36.1 years for men and 34.2 years for women, $\mathrm{p}<0.001$ ). The mean screening CD4 cell count was 15 cells $/ \mathrm{mm}^{3}$ higher among women (169.8 versus 155.0 cells $/ \mathrm{mm}^{3}$ among men). Women also had lower mean hemoglobin levels than men $(\mathrm{p}<0.001)$.

Among the 740 women enrolled in the study, $32(4.3 \%)$ had a history of an AIDS-defining illness (ADI) compared to $97(11.9 \%$ ) of the $831 \mathrm{men}$ ( $\mathrm{p}<0.001)$. After controlling for screening CD4 cell count and stratifying by country, men had significantly greater odds of having a prior AIDS-defining illness diagnosis (OR=2.1, 95\% CI 1.4-3.3), Pneumocystis jiroveci pneumonia (OR=4.5, 95\% CI 1.0-20.0), or herpes simplex ulcers $(\mathrm{OR}=3.0,95 \% \mathrm{CI}$ 1.1-7.7). Participants with a prior ADI had higher mean baseline HIV-1 RNA levels (5.1 vs. $4.9 \log _{10}$ copies $/ \mathrm{mL}$ ).

The unadjusted mean HIV-1 RNA level was $5.05 \log _{10}$ copies $/ \mathrm{mL}$ in men compared to 4.85 $\log _{10}$ copies $/ \mathrm{mL}$ in women $(\mathrm{p}<0.001)$. Only $11(1 \%)$ study participants entered the study with a baseline plasma HIV-1 RNA level of $<400$ copies $/ \mathrm{mL}$ (i.e., with a left-censored RNA value), and 121 (8\%) participants had a baseline viral load $>750,000$ copies $/ \mathrm{mL}$. On average, women had a $0.20 \log _{10}$ lower baseline RNA level than men $(\mathrm{p}<0.0001)$. The malefemale difference in HIV-1 RNA level varied by CD4 cell count ( $\mathrm{p}=0.04)$, in a linear regression model that adjusted for country, AIDS history, TB history and age (Figure 1). Plasma HIV-1 RNA level sex differences were not associated with country ( $\mathrm{p}=0.9$ for the 2way interaction between country and sex). The countries with the greatest magnitude of difference in viral load by sex were Haiti, Zimbabwe, India and Malawi (Table 2). Prior antiretroviral use did not explain the lower viral loads in women: only $4.7 \%$ of the women had more than seven days of previous exposure to antiretroviral drugs, and only two men reported any antiretroviral use.

\section{Discussion}

Our results demonstrate important differences in the clinical, immunological and virologic characteristics of HIV-positive men and women with CD4 cell counts below 300 cells $/ \mathrm{mm}^{3}$ presenting for the initiation of ART in diverse parts of the world. The finding that female sex was independently associated with lower plasma HIV-1 RNA levels is more likely due to inherent biological differences between men and women than factors linked to geographic location, including race, co-infections, culture and environment. The magnitude of the sex difference in plasma HIV-1 RNA levels appeared to be partially mediated by CD4 cell count, with a greater difference in the highest CD4 cell count strata in this population with CD4 $<300$ cells $/ \mathrm{mm}^{3}$. Although it was not statistically significant, we observed heterogeneity in the magnitude of the sex difference in viral load in different countries.

Previous reports from the developed world have described sex-based differences in plasma HIV-1 viral load levels and in the rate of CD4+ cell depletion after seroconversion ${ }^{2-5}$. Also, a study from Thailand that included a large number of Thai men and women with the non-B 
HIV subtype found no sex-based differences in HIV RNA levels after adjusting for CD4 count ${ }^{6}$ Prior studies have demonstrated that viral load differences tend to dissipate several years after seroconversion, at which point rates of progression to AIDS are similar by sex. ${ }^{8}$. Data from studies evaluating the effect of sex on disease progression in seroconverter cohorts of men and women in the pre-HAART era showed that, compared to men, women appeared to have lower HIV RNA levels and higher CD4 cell counts shortly after infection with $\mathrm{HIV}^{9}$.

In a study from the Cascade collaboration that enrolled 1864 individuals with known seroconvertion dates, women infected heterosexually and through injecting drug use, had an average $34 \%$ [95\% confidence interval (CI), 2.3-56\%] and 46\% (95\% CI, 17-66\%) lower HIV RNA load respectively, compared to men in the same risk group ${ }^{10}$.

In this study, we observed a sex difference in plasma HIV RNA levels even among patients with more advanced disease and CD4 cell counts $<200$ cells $/ \mathrm{mm}^{3}$.

A review of 13 studies (4 of which were longitudinal) confirmed these findings, which were unchanged after adjustment for potential confounding variables, such as age, race, mode of transmission, and use of $\mathrm{ART}^{7}$. Intuitively, lower levels of circulating plasma HIV RNA viral load, which suggest lower steady-state levels of viremia, should be associated with better outcomes. However, the lower plasma HIV RNA level seen in women does not appear to provide benefits in terms of disease progression or survival. ${ }^{8}$

Hormonal differences have been cited as possible factors contributing to sex-related differences in viral load $2,10,11$. Estrogen has been found to inhibit production of tumor necrosis factor alpha (TNF- $\alpha)^{13}$, and this could result in decreased viral replication in women ${ }^{14}$. However, it does not explain the reversal of the sex difference as the disease progresses. Moreover, there is no significant change in levels of HIV-1 RNA in women over the course of the menstrual cycle, despite the associated hormonal changes ${ }^{15}$ In addition, a sex-based difference in the levels of HIV-1 RNA is seen in infant boys and girls, in whom the hormonal milieu is similar ${ }^{16}$

The biological mechanism underlying the lower (compared to men) viral loads in women that occur at higher CD4 $\mathrm{T}$ cell counts may reflect a sex-related difference in the state of immune activation. Women generally experience more effective cell-mediated immunity than men (from soon after birth) ${ }^{17}$. Therefore, greater control of viral reproduction in the early stages of HIV/AIDS may be a manifestation of this nonspecific sex difference in immunity. Notably, in one study, the lower levels of HIV-1 RNA in women did not appear to be mediated by stronger CD8+ effector responses ${ }^{18}$. The lower density of CCR5 on CD4+ lymphocytes in women may play a role ${ }^{19}$, but more data are needed to investigate this possibility.

Of note there were higher rates of HSV-2 infection found among the men in this study, and we cannot exclude the possibility that this may have contributed to the higher HIV viral load observed among the men.

The sex differences in the baseline hemoglobin and platelet counts were not unexpected; however, the lower creatinine clearance among women, despite being within the normal range $(100 \mathrm{~mL} / \mathrm{min}$ in women compared to $106 \mathrm{~mL} / \mathrm{min}$ in men), is of uncertain clinical significance. It is important to remember that female sex has been previously described as a traditional risk factor for renal damage, both in the HIV-positive and HIV-negative populations $20,21,22$. Female sex has been shown to be associated with a greater risk of low eGFR values in ARV-naïve patients and to remain associated with a higher risk of eGFR decline from pre-ART values among patients who initiated HAART ${ }^{23}$.Toxicity 
management among women should take these considerations into account, particularly in those settings where tenofovir is widely used.

The PEARLS study is one of the largest and most ethnically and geographically diverse cohorts of HIV-1 infected patients ever recruited into an HIV-1 ART trial. It provides a unique opportunity for comparisons between men and women with CD4 cell counts < 300 cells $/ \mathrm{mm}^{3}$ at initiation of ART in diverse areas of the world. All viral load and CD4 cell measurements used in the study were performed in laboratories that used similar methodologies and participated in centralized quality assurance programs, which provided consistency of results sites. The higher prevalence of AIDS-defining illnesses among men suggests that the men presenting for treatment had more advanced disease than the women. This result may be partially explained by the more widespread screening of women during pregnancy, which may lead to earlier detection of disease, or by greater health-care-seeking behavior in women compared to men in developing countries.

Our study has several important limitations. First, because this is a large study, we were able to detect statistically significant differences in some of the examined parameters that may not be clinically meaningful. Second, the eligibility criteria for enrollment into the clinical trials were required to be within a normal range, limiting our ability to examine sex differences in laboratory values for men and women presenting for care. Third, the crosssectional design of this analysis and the absence of data on the date of seroconversion limit the conclusions we can draw about rates of disease progression in women compared to men. Moreover, the advanced immunodeficiency status of the study patients may also limit the scope of the results presented here regarding sex differences and HIV natural history. However, our findings do extend earlier observations demonstrating lower levels of HIV-1 RNA in women compared to men in resource-limited settings. The biological mechanisms underlying the lower viral load levels in women remain unexplained. The association between baseline viral load, sex and response to ART will be further investigated in the follow-up of participants in the PEARLS study.

\section{Acknowledgments}

Sponsorship:

The project described was supported by Award Number U01AI068636 from the National Institute of Allergy and Infectious Diseases and supported by National Institute of Mental Health (NIMH), National Institute of Dental and Craniofacial Research (NIDCR).This work was supported by grants AI69532, AI69424, AI69511, AI69428, AI27661, AI69484, AI69495, AI69474, AI69513, AI69471, AI25915, AI46370, AI69472, AI46381, AI69423, AI25868, AI69439, AI46376, AI38858-09S1, AI34853, AI69450, AI69467, AI32782, AI69419, AI69463, AI69426, AI69438, AI69399, AI69417, AI69432, AI69518, AI69476, AI69401, AI69421, AI69518, AI69436, AI69470

The collaborating pharmaceutical supporters were Boehringer Ingelheim Pharmaceuticals Inc., Bristol-Myers Squibb Inc., Gilead Sciences Inc., GlaxoSmithKline, Merck \& Co. Inc

The content is solely the responsibility of the authors and does not necessarily represent the official views of the National Institute of Allergy and Infectious Diseases or the National Institutes of Health.

\section{References}

1. Joint United Nations Programme on HIV/AIDS (UNAIDS). World Health Organization (WHO). AIDS epidemic update. Switzerland: UNAIDS/WHO, Geneva; 2009 December.

2. Farzadegan H, Hoover DR, Astemborski J, et al. Sex differences in HIV-1 viral load and progression to AIDS. Lancet. 1998; 352:1510-1514. [PubMed: 9820299]

3. Gandhi M, Bacchetti P, Miotti P, et al. Does Patient Sex Affect Human Immunodeficiency Virus Levels? Clin Infect Dis. 2002; 35:313-322. [PubMed: 12115098] 
4. Rezza G, Lepri AC, D’Arminio Monforte A, et al. Plasma viral load concentrations in women and men from different exposure categories and with known duration of HIV infection. ICONA Study Group. J AIDS. 2000; 25:56-62.

5. Moore AL, Kirk O, Johnson AM, et al. Virologic, immunologic, and clinical response to highly active antiretroviral therapy: the gender issue revisited. J AIDS. 2003; 32:452-461.

6. Trichavaroj R, de Souza MS, Buapunth P, Markowitz L, Sukwit S, Nitayaphan S, Brown AE. J Acquir Immune Defic Syndr. 2001 Apr 1; 26(4):345-347. HIV viral load in Thai men and women with subtype E infections. [PubMed: 11317076]

7. Napravnik S, Poole C, Thomas JC, et al. Gender difference in HIV RNA levels: a meta-analysis of published studies. J AIDS. 2002; 31:11-19.

8. Sterling TR, Vlahov D, Astemborski J, et al. Initial plasma HIV-1 RNA levels and progression to AIDS in women and men. N Engl J Med. 2001; 344(10):720-725. [PubMed: 11236775]

9. Prins M, Meyer L, Hessol NA. Sex and the course of HIV infection in the pre- and highly active antiretroviral therapy eras. AIDS. 2005 Mar 4; 19(4):357-370. [PubMed: 15750389]

10. Touloumi G, Pantazis N, Babiker AG, Walker SA, Katsarou O, Karafoulidou A, Hatzakis A, Porter K. CASCADE Collaboration Differences in HIV RNA levels before the initiation of antiretroviral therapy among 1864 individuals with known HIV-1 seroconversion dates. AIDS. 2004 Aug 20; 18(12):1697-1705. [PubMed: 15280781]

11. Sterling TR, Lyles CM, Vlahov D, et al. Sex differences in longitudinal human immunodeficiency virus type 1 RNA levels among seroconverters. J Infect Dis. 1999; 180:666-672. [PubMed: 10438353]

12. Anastos K, Gange SJ, Lau B, et al. Association of race and gender with HIV-1 RNA levels and immunologic progression. J Acquir Immune Defic Syndr. 2000; 24:218-226. [PubMed: 10969345]

13. Shanker G, Sorci-Thomas M, Adams MR. Estrogen modulates the expression of tumor necrosis factor alpha mRNA in phorbol ester-stimulated human monocytic THP-1 cells. Lymphokine Cytokine Res. 1994; 13:377-382. [PubMed: 7703311]

14. Mellors JW, Griffith BP, Ortiz MA, et al. Tumor necrosis factoralpha/ cachectin enhances human immunodeficiency virus type 1 replication in primary macrophages. J Infect Dis. 1991; 163:78-82. [PubMed: 1984479]

15. Reichelderfer PS, Coombs RW, Wright DJ, et al. Effect of menstrual cycle on HIV-1 levels in the peripheral blood and genital tract. WHS 001 Study Team. AIDS. 2000; 14:2101-2107. [PubMed: 11061650]

16. Pitt, J.; Moye, J.; Matthews, Y., et al. Sex differences in immunologic and virologic markers in children born to women infected by human immunodeficiency virus (HIV) (abstract 513]. 8th Conference on Retroviruses and Opportunistic Infections (Chicago); Foundation for Retrovirology and Human Health; Alexandria, VA. 2001.

17. Rhodes K, Scott A, Markhan RL, et al. Immunological sex differences. Ann Rheum Dis. 1969; 28:104-120. [PubMed: 4180579]

18. Sex-based differences in T lymphocyte responses in HIV-1-seropositive individuals. Sterling TR, Pisell-Noland T, Perez JL, Astemborski J, McGriff JR, Nutting L, Hoover DR, Vlahov D, Bollinger RC. J Infect Dis. 2005 Mar 15; 191(6):881-885. [PubMed: 15717262]

19. Portales P, Clot J, Corbeau P. Sex differences in HIV-1 viral load due to sex difference in CCR5 expression. Ann Intern Med. 2001; 134:81-82. [PubMed: 11187428]

20. Overton ET, Nurutdinova D, Freeman J, et al. Factors associated with renal dysfunction within an urban HIV-infected cohort in the era of highly active antiretroviral therapy. HIV Med. 2009; 10:343-350. [PubMed: 19490182]

21. Lucas GM, Lau B, Atta MG, et al. Chronic kidney disease incidence and progression to end-stage renal disease in HIV-infected individuals: a tale of two races. J Infect Dis. 2008; 197:1548-1557. [PubMed: 18422458]

22. Prevalence and factors associated with renal impairment in HIV-infected patients, ANRS C03 Aquitaine Cohort, France. Déti EK, Thiébaut R, Bonnet F, Lawson-Ayayi S, Dupon M, Neau D, Pellegrin JL, Malvy D, Tchamgoué S, Dabis F, Morlat P. Groupe d'Epidémiologie Clinique du SIDA en Aquitaine. HIV Med. 2010 May; 11(5):308-317. [PubMed: 20002500] 
23. Evaluation of glomerular filtration rate in HIV-1-infected patients before and after combined antiretroviral therapy exposure. Tordato F, Cozzi Lepri A, Cicconi P, De Luca A, Antinori A, Colangeli V, Castagna A, Nasta P, Ladisa N, Giacometti A, d'Arminio Monforte A, Gori A. ICONA Foundation Study Group. 


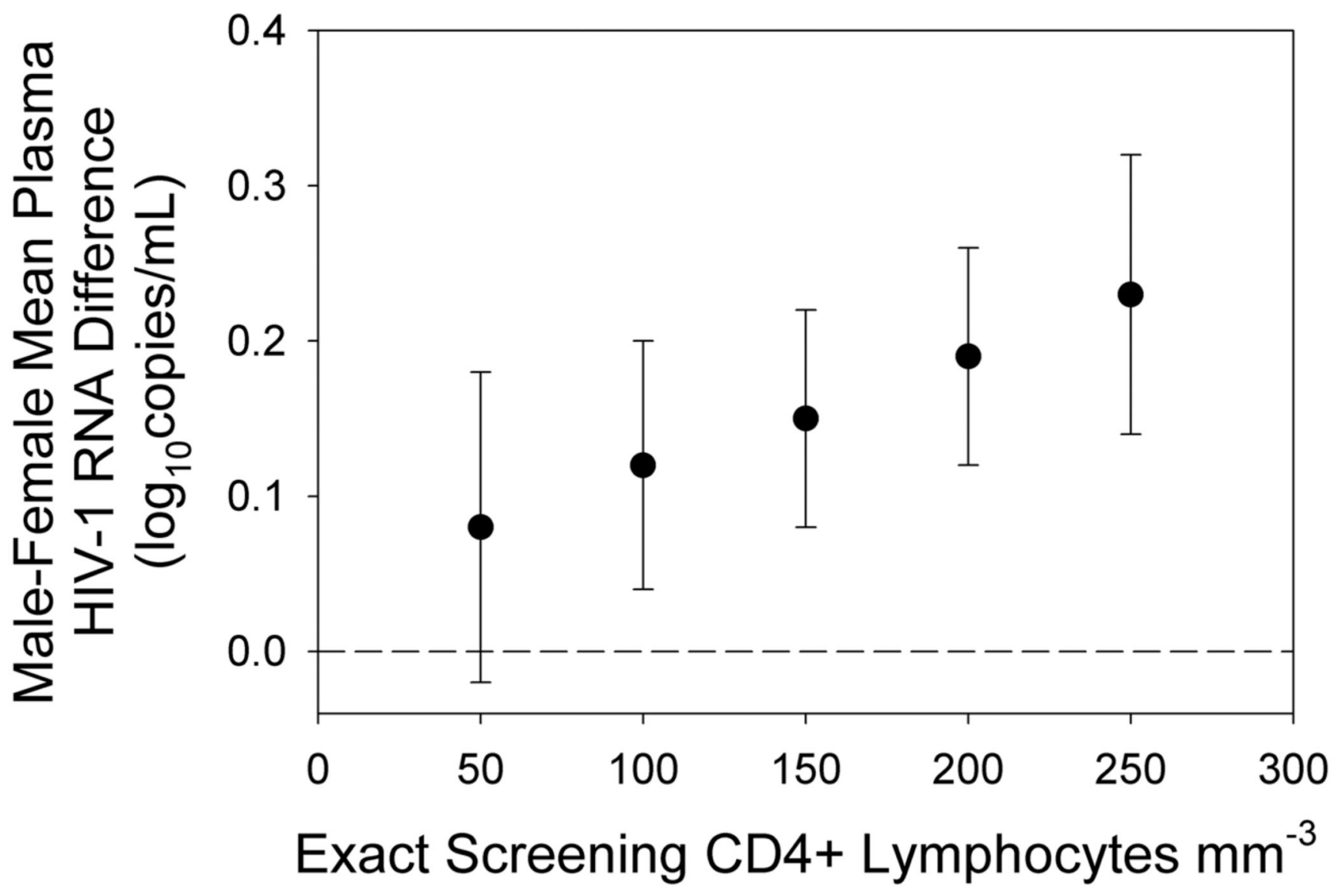

FIGURE 1.

Relationship of plasma HIV-1 RNA concentration between men and women to CD4+ lymphocyte count. The regression model is adjusted for country, AIDS history, TB history and age. Error bars show 95\% confidence intervals on the estimated difference in mean viral load between mean and women. 
TABLE 1

Baseline Characteristics by Sex

\begin{tabular}{|c|c|c|c|}
\hline Characteristics & Men $(\mathbf{N}=\mathbf{8 3 1})$ & Women $(N=740)$ & $\mathbf{P}$ \\
\hline Age (years) - Mean (S.D.) & $36.1(8.8)$ & $34.2(8.3)$ & $<0.001$ \\
\hline Weight $(\mathrm{kg})$ - mean (s.d.) & $66.3(13.6)$ & $58.5(13.3)$ & $<0.001$ \\
\hline BMI - Mean (S.D.) & $22.7(3.7)$ & $23.6(5.0)$ & $<0.001$ \\
\hline Hemoglobin (g/dL) - Mean (S.D.) & $13.3(1.9)$ & $11.5(1.5)$ & $<0.001$ \\
\hline Albumin (g/dL) - Mean (S.D.) & $4.0(0.8)$ & $3.8(0.7)$ & $<0.001$ \\
\hline Creatinine Clearance (mL/min) - Mean (S.D.) & $106.2(34.2)$ & $100.5(30.3)$ & $<0.001$ \\
\hline CD4+ lymphocytes (mm3) - Mean (S.D.) & $155.0(86.3)$ & $169.8(79.0)$ & $<0.001$ \\
\hline Plasma HIV-1 RNA $(\log 10 \mathrm{c} / \mathrm{mL})$ - Mean (S.D.) & $5.1(0.6)$ & $4.9(0.7)$ & $<0.001$ \\
\hline Country strata - no. $(\%)$ & & & $<0.001$ \\
\hline Brazil & $148(17.8)$ & $83(11.2)$ & \\
\hline Haiti & $52(6.3)$ & $48(6.5)$ & \\
\hline India & $144(17.3)$ & $111(15.0)$ & \\
\hline Malawi & $72(8.7)$ & $149(20.1)$ & \\
\hline Peru & 89 (10.7) & $45(6.1)$ & \\
\hline South Africa & $69(8.3)$ & $141(19.1)$ & \\
\hline Thailand & $45(5.4)$ & $55(7.4)$ & \\
\hline United States & $172(20.7)$ & $38(5.1)$ & \\
\hline Zimbabwe & $40(4.8)$ & $70(9.5)$ & \\
\hline \multicolumn{4}{|l|}{ Baseline AIDS Diagnosis status - no. (\%) } \\
\hline No prior AIDS dx reported & $733(88.2)$ & $708(95.7)$ & $<0.001$ \\
\hline Prior AIDS dx - not ongoing & $51(6.1)$ & $17(2.3)$ & \\
\hline Prior AIDS dx - ongoing & $46(5.5)$ & $15(2.0)$ & \\
\hline \multicolumn{4}{|l|}{ Karnofsky score - no. (\%) } \\
\hline 100 & $302(36)$ & $299(40)$ & 0.07 \\
\hline 90 & $462(56)$ & $399(54)$ & \\
\hline 80 & $58(7)$ & $40(5)$ & \\
\hline 70 & $9(1)$ & $2(0)$ & \\
\hline \multicolumn{4}{|l|}{ HBV surface antigen - no. (\%) } \\
\hline Positive & $55(6.6)$ & $35(4.7)$ & 0.16 \\
\hline \multicolumn{4}{|l|}{ Any history of TB? - no. (\%) } \\
\hline Yes & $150(18.1)$ & $129(17.2)$ & 0.7 \\
\hline
\end{tabular}


TABLE 2

Estimated mean RNAs (from a model adjusting only for CD4 and gender) where separate models fitted for each country*

\begin{tabular}{lrrrr}
\hline Country & $\begin{array}{r}\text { Estimated } \\
\text { Sex effect } \\
\text { (men-women) }\end{array}$ & $\begin{array}{r}\text { Estimated } \\
\text { Mean } \\
\text { difference } \\
\text { (men- }\end{array}$ & $\begin{array}{r}\text { Men } \\
(\mathbf{N})\end{array}$ & $\begin{array}{r}\text { Women } \\
(\mathbf{N})\end{array}$ \\
$\begin{array}{l}\text { women) at } \\
\text { CD4 }=\mathbf{1 7 0}\end{array}$ & & \\
\hline Brazil & 0.06 & 0.15 & 148 & 83 \\
Haiti & 0.18 & 0.29 & 52 & 48 \\
India & 0.08 & 0.20 & 144 & 111 \\
Malawi & -0.17 & 0.25 & 72 & 149 \\
Peru & 0.12 & 0.01 & 89 & 45 \\
South Africa & -0.32 & 0.10 & 69 & 141 \\
Thailand & -0.11 & 0.16 & 45 & 55 \\
United States & 0.44 & 0.14 & 172 & 38 \\
Zimbabwe & 0.11 & 0.25 & 40 & 70 \\
\hline
\end{tabular}

* Note: separate models by country not justified by a significant country by sex interaction $(\mathrm{p}=0.9)$ or cd 4 by country interaction. $(\mathrm{p}=0.6)$ 